\title{
Continuous positive airway pressure in bronchiolitis
}

\author{
JENNIFER M BEASLEY, SUSAN E F JONES
}

\begin{abstract}
Over five years 23 infants with evidence of respiratory insufficiency due to bronchiolitis were managed with continuous positive airway pressure (CPAP). This was applied through either a short nasal cannula (14 patients) or an endotracheal tube (nine patients). Clinical improvement was seen in all patients, and there were significant falls in mean respiratory and pulse rates and pressure of carbon dioxide $\left(\mathrm{PCO}_{2}\right)$. Seven infants with $\mathrm{PCO}_{2}$ values exceeding $8.0 \mathrm{kPa}(60.2 \mathrm{~mm} \mathrm{Hg})$ responded particularly well.
\end{abstract}

CPAP is effective in bronchiolitis, and when applied by the nasal route it is relatively free from complications.

\section{Introduction}

Bronchiolitis is an epidemic viral illness occurring mainly in infants under 6 months. Though the condition is relatively mild in most cases, reported mortality rates vary from $0.7 \%$ to $5.5 \% \cdot{ }^{1-3}$ Respiratory failure occurs in $2 \cdot 0-5 \cdot 0 \%$ of patients admitted to hospital ${ }^{4-6}$ and is suggested clinically by a rising respiratory rate, increasing effort, apnoeic attacks, a rising pulse rate, and restlessness. Biochemically, respiratory failure may be defined as a pressure of arterial carbon dioxide $\left(\mathrm{PaCO}_{2}\right)$ above $6.5 \mathrm{kPa}(48.9 \mathrm{~mm} \mathrm{Hg})^{7}{ }^{8}$ or a pressure of arterial oxygen $\left(\mathrm{PaO}_{2}\right)$ below $8.0 \mathrm{kPa}(60.2 \mathrm{~mm} \mathrm{Hg}),{ }^{79}$ or both. Such a $\mathrm{PaCO}_{2}$ is probably unrealistic in bronchiolitis, as many infants tolerate higher values and recover uneventfully. The usual treatment for severe respiratory failure, as assessed clinically and from blood gas tensions, is intermittent positive-pressure ventilation.

Between 1970 and 1975, 288 infants with bronchiolitis were admitted to this hospital; of these, 13 were treated by intermittent positive-pressure ventilation. One death occurred, and three other patients had severe complications. Concerned by these results, we have since requested earlier participation and have pursued a policy of intervening sooner in patients who deteriorate clinically. Most of these infants have been managed with continuous positive airway pressure (CPAP), usually applied through a single nasal cannula or, if this fails, an endotracheal tube. We report the results of 23 infants managed in this way, 14 of them by nasal CPAP alone.

\section{Patients and methods}

During 1976-80 we used CPAP as the main form of respiratory support given to referred patients (table I). All the patients were considered to have uncomplicated bronchiolitis with tachypnoea, wheezing, and hyperinflated lungs. Respiratory syncytial virus was isolated in 10 patients and cytomegalovirus in one. Seventeen of the infants were aged 2 months or younger, three were between 2 and 6 months, and three 6 to 11 months.

Before referral all patients were nursed in oxygen, and most were given fluids intravenously rather than by mouth. Regular observations of their condition were made, and blood gas estimations were per-

\section{Children's Hospital, Birmingham B16 8ET}

JENNIFER M BEASLEY, FFARACS, consultant anaesthetist SUSAN E F JONES, FFARCS, consultant anaesthetist
TABLE I-Main forms of respiratory support for bronchiolitis. Figures are numbers of patients

\begin{tabular}{lccccc}
\hline & \multirow{2}{*}{$\begin{array}{c}\text { Total } \\
\text { No }\end{array}$} & $\begin{array}{c}\text { Intermittent } \\
\text { positive- } \\
\text { pressure }\end{array}$ & \multicolumn{2}{c}{ CPAP } & Lavage \\
ventilation & $\begin{array}{c}\text { Endotracheal } \\
\text { tube }\end{array}$ & $\begin{array}{c}\text { Nasal } \\
\text { cannula }\end{array}$ & \\
\hline $1970-5$ & 288 & 13 & 2 & 14 & 5 \\
$1976-80$ & 305 & 2 & 7 & 14 & \\
\hline
\end{tabular}

CPAP $=$ Continuous positive airway pressure.

formed at frequent intervals, especially when the infant was showing signs of increasing distress.

The patients were usually referred by the paediatricians because of increasing sternal recession, restlessness despite oxygen, and diminishing breath sounds. Some were referred because of increasing hypercapnia, and some because of recurrent apnoeic attacks, often after pharyngeal suction or a feed. Fewer than half of the infants referred were thought to be ill enough to warrant respiratory support. A pressure of carbon dioxide $\left(\mathrm{PCO}_{2}\right)$ exceeding $8.0 \mathrm{kPa}(60.2 \mathrm{~mm} \mathrm{Hg})$ was not regarded as sufficient justification if the infant was alert and lively.

Criteria for respiratory support-Increasing effort, a rising pulse rate, especially when combined with a rising respiratory rate, altered consciousness, and lethargy were considered to be the most important clinical indications for respiratory support. The $\mathrm{PCO}_{2}$, though always raised, did not necessarily reflect the severity of the distress.

$C P A P$ (fig 1) was applied nasally in the first instance via a single nasal cannula $2-3 \mathrm{~cm}$ long. An ordinary plastic endotracheal tube of suitable diameter was cut down to this length and fixed in the nostril.

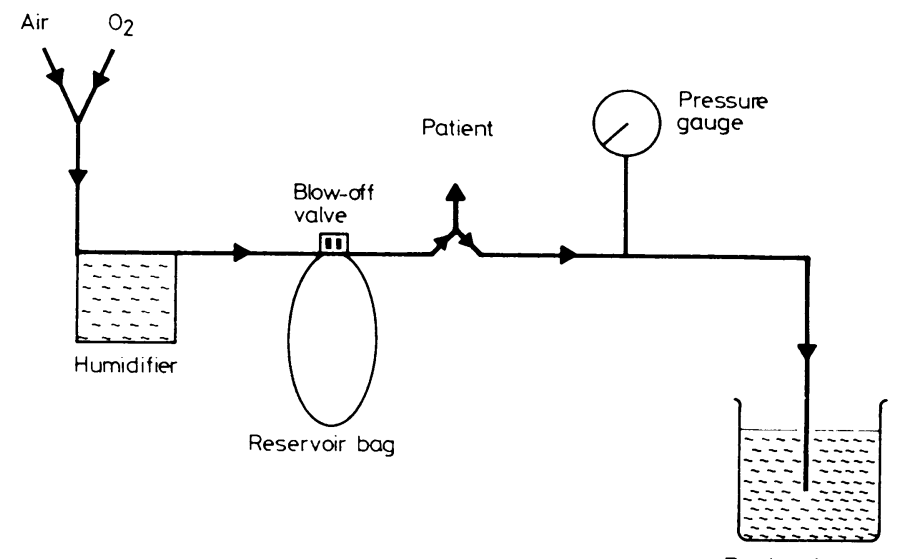

FIG 1 -CPAP system.

The pressure applied was usually $5 \mathrm{~cm} \mathrm{H}_{2} \mathrm{O}$, which was read at the nasal connector. A mixture of $30-40^{\circ}$ oxygen in air was given and the patients were not sedated. The amount of pressure could be varied by altering the water level, and gas flow was adjusted to give constant bubbling in the bottle. If nasal CPAP failed to produce relief, or if bronchial secretions were excessive, the infant was intubated with a nasotracheal plastic tube, usually under general anaesthesia. After careful suction of the trachea CPAP was applied via the endotracheal tube, again using $5 \mathrm{~cm} \mathrm{H}_{2} \mathrm{O}$. Pulse and respiratory rates were monitored closely afterwards, and blood gas tensions were measured within three hours.

Statistical-Differences in $\mathrm{PCO}_{2}$ and pulse and respiratory rates before and after beginning CPAP were analysed with the paired Student's $t$ test. 


\section{Results}

Of the 23 patients managed with CPAP, nine were intubated; the mean duration of support was $5 \cdot 2$ days. In 1975 two infants were intubated from the start, as nasal CPAP had not been introduced. One patient arrived intubated from another hospital, and three others were intubated because of excessive secretions. These infants were subsequently extubated and continued with nasal CPAP. In three patients nasal CPAP failed to improve the respiratory distress, and they were then intubated. The other 14 patients were managed with nasal CPAP alone, and the mean duration of support was 3.3 days. Clinical improvement was usually immediate, with a reduction in rib and sternal recession and a drop in respiratory and pulse rates.

Blood gases-Most analyses were performed on capillary samples, though some patients had arterial punctures. In two patients who had recurrent apnoeic episodes, CPAP was started before the relevant blood gases could be measured. This was also the case in the already intubated infant. Figure 2 gives the $\mathrm{PCO}_{2}$ results of the remaining 20 patients. All the infants had raised values before CPAP, and the group mean fell from 7.85 to $6.30 \mathrm{kPa}(59.0$ to $47.4 \mathrm{~mm} \mathrm{Hg})$ over the next three hours $(p<0.01)$. In two patients the $\mathrm{PCO}_{2}$ rose slightly but decreased within a further two hours. Seven patients had $\mathrm{PCO}_{2}$ values above $8.0 \mathrm{kPa}(60.2 \mathrm{~mm} \mathrm{Hg})$, and this group showed the greatest mean fall after CPAP (table II). Three were given nasal CPAP alone, three

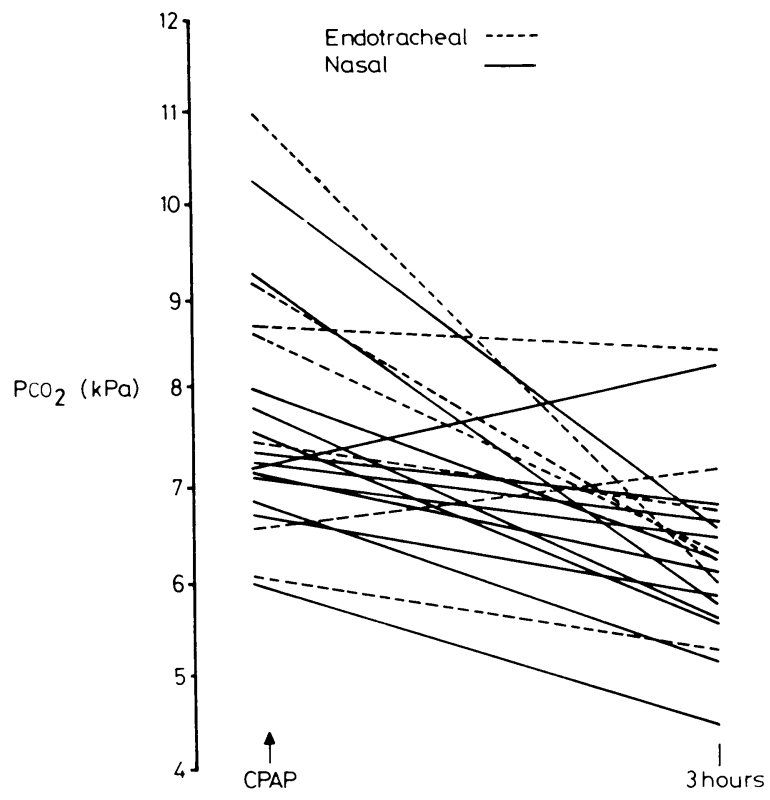

FIG $2-\mathrm{PCO}_{2}$ values in 20 infants at start and three hours after

CPAP. Mean fall at three hours 1.54 SEM $0.33 \mathrm{kPa}(11.6$

SEM $2.5 \mathrm{~mm} \mathrm{Hg} ; \mathrm{p}<0.01$ ).

Conversion: SI to traditional units $-\mathrm{PCO}_{2}: 1 \mathrm{kPa} \approx 7.5 \mathrm{~mm} \mathrm{Hg}$

TABLE II-PCO ${ }_{2}$ ralues before and after $C P A P$ in seven infants with bronchiolitis whose initial $\mathrm{PCO}_{2}$ values exceeded $8.0 \mathrm{kPa}(60.2 \mathrm{~mm} \mathrm{Hg})$

\begin{tabular}{|c|c|c|c|c|c|c|c|c|}
\hline & \multicolumn{3}{|c|}{ Before } & \multicolumn{3}{|c|}{ After } & \multirow{2}{*}{$\begin{array}{l}\text { Mean } \\
\text { fall } \\
\text { SEM }\end{array}$} & \multirow{2}{*}{$\mathrm{p}$} \\
\hline & Mean & SI) & Range & Mean & S1) & Range & & \\
\hline $\mathrm{Pa})$ & $9 \cdot 33$ & $1 \cdot 01$ & $8 \cdot 06-11 \cdot 02$ & 6.53: & 0.91 & $5 \cdot 80-8 \cdot 50$ & $2.80: 0.57$ & 0 . \\
\hline
\end{tabular}

Concersion: SI to traditional units-PCO.: $1 \mathrm{kPa} \approx 7.5 \mathrm{~mm} \mathrm{Hg}$.

were intubated from the start, and one failed to improve clinically with nasal CPAP and was intubated. The mean hydrogen ion concentration fell from $46 \cdot 6$ to $41.7 \mathrm{nmol} / 1(4.7$ to $4 \cdot 2 \mathrm{ng} / 100 \mathrm{ml})$. These comparatively low values were partly related to raised standard bicarbonate concentrations in some patients, indicating that a degree of compensation had occurred. The $\mathrm{PaO}_{2}$ values for the series were incomplete.

Pulse and respiratory rates (fig 3) were measured just before the application of CPAP and two hours later. Rates in the patient who was already intubated are excluded. The mean pulse rate fell from
163 to 140 beats/min, and the mean respiratory rate fell from 69 to $53 \mathrm{breaths} / \mathrm{min}$. Both falls were significant $(\mathrm{p}<0.01)$. The respiratory rate increased initially in two patients, but dropped three hours later; and in one patient, aged 6 weeks, the pulse rate rose from 130 to 145 beats/min.

Complications-One infant had a small pneumothorax, discovered on chest radiography, which was drained. There were no deaths.
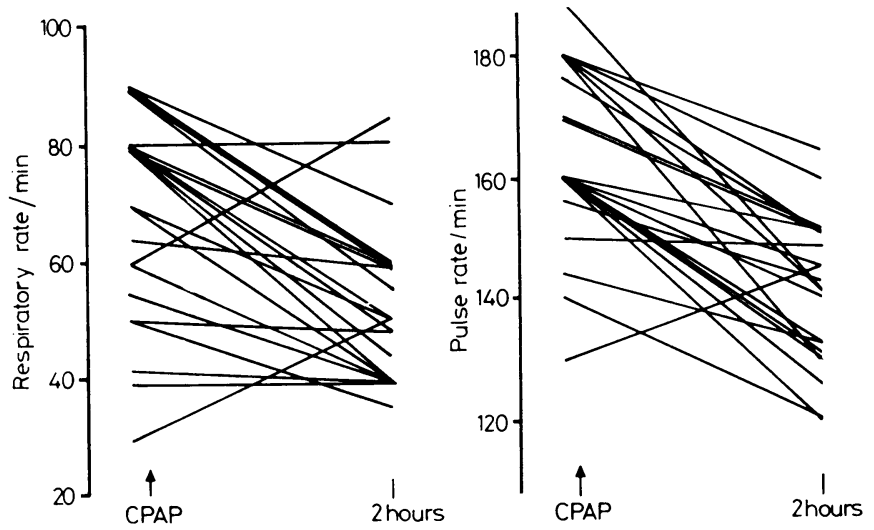

FIG 3-Respiratory and pulse rates at start and two hours after CPAP. Mean fall in respiratory rate at two hours 20.1 SEM 3.86 breaths/min $(p<0.01)$. Mean fall in pulse rate at two hours $24.6 \pm$ SEM 3.26 beats $/ \mathrm{min}$ $(\mathrm{p}<0.01)$.

\section{Discussion}

CPAP is widely used in other respiratory conditions of infancy but does not appear to have been reported in bronchiolitis. In this condition the peripheral airways are most severely affected by inflammation; obstruction of the lumen is greatest during expiration, and air trapping occurs. ${ }^{10} 11$ Most infants compensate for the increased physiological dead space to tidal volume ratio by increasing the minute volume. As the infant becomes exhausted, however, the minute volume falls to basal values and the $\mathrm{PCO}_{2}$ rises. ${ }^{6}$ This is invariably accompanied by hypoxaemia, which is aggravated by a rising respiratory rate. ${ }^{12}$ At this stage the infant may improve considerably with oxygen or may progress to severe respiratory failure. Simpson and Flenley ${ }^{13}$ regarded a $\mathrm{PCO}_{2}$ exceeding $8.7 \mathrm{kPa}(65.4 \mathrm{~mm} \mathrm{Hg})$ and a hydrogen ion concentration exceeding $63 \mathrm{nmol} / 1(6.4 \mathrm{ng} / 100 \mathrm{ml})$ in unventilated patients as signs of grave prognostic importance.

The decision to ventilate may be based on clinical grounds alone ${ }^{5}$ or on clinical signs and blood gas tensions. ${ }^{614}$ Artificial ventilation, though undoubtedly reducing the mortality, is not without its own hazards. Muscle relaxation is usually required ${ }^{6} 15$ to ensure adequate gas exchange. Tube blockage, ${ }^{5}$ pneumothorax and subglottic stenosis, ${ }^{6}$ and severe secondary infection ${ }^{6} 1415$ have been reported. Several deaths have occurred. ${ }^{514}$

Of the 13 patients ventilated at this hospital before 1976, one died without regaining consciousness, two had neurological sequelae as a result of cardiac arrest before intermittent positivepressure ventilation, and one developed subglottic stenosis. The mean peak $\mathrm{PCO}_{2}$ of these patients was $11.7 \pm \mathrm{SD} 2.67 \mathrm{kPa}$ $(88 \cdot 0.20 \cdot 1 \mathrm{~mm} \mathrm{Hg})$, the mean hydrogen ion concentration $66.7 \mathrm{SD} 13.5 \mathrm{nmol} / \mathrm{l}(6.7-1.4 \mathrm{ng} / 100 \mathrm{ml})$, and the mean duration of ventilation six days.

After 1976 we ventilated only two patients with bronchiolitis. Both had congenital heart disease (ventricular septal defect, patent ductus arteriosus) and were ventilated from the beginning. In those managed entirely with CPAP we intervened early before most infants developed severe uncompensated respiratory failure. The decision to intervene was made on clinical grounds alone, though all patients had raised $\mathrm{PCO}_{2}$ values. A significant fall in $\mathrm{PCO}_{2}$ in the group as a whole occurred within three hours after instituting CPAP, and in the group with higher initial readings the fall was more dramatic, from a mean of $9.33 \mathrm{kPa}$ 
to $6.53 \mathrm{kPa}(70.2$ to $49.1 \mathrm{~mm} \mathrm{Hg})$. Despite this, individual values did not correlate well with the infant's condition, especially beforehand. This agrees with the view of Phelan $e t$ al ${ }^{5}$ that there is no absolute value of $\mathrm{Pco}_{2}$ to indicate the need for intermittent positive-pressure ventilation.

Clinical improvement, though more difficult to assess objectively, was very obvious. The patients appeared more settled, sternal recession decreased, and cyanosis, when present, usually disappeared. The pulse and respiratory rates of the group had decreased significantly after two hours $(p<0.01)$. All patients were improved by CPAP, and in none was ventilation considered as an alternative. CPAP increases the functional residual capacity and thereby enlarges the diameter of all the airways. Raised intraluminal pressure also prevents poorly supported small airways from collapsing during increased expiratory effort. ${ }^{16}$ At first, applying a distending pressure to the already overdistended lungs of a baby with bronchiolitis seems to be a wrong principle; presumably CPAP widens the terminal airways enough to allow deflation to occur.

Quite probably some of these infants would have recovered without any intervention, but it is highly unlikely that they all would. The intervention rate during $1976-80$ was $7 \cdot 5 \%$, compared with $6.9 \%$ during 1970-5, when all the patients treated had severe respiratory failure, including those subjected to bronchial lavage. Even allowing for possible differences in the nature of the disease, probably many of the infants managed with CPAP would have progressed to a critical state without early intervention.

Nasal CPAP is easy to apply, non-invasive, and relatively free from complications. The patient may need an endotracheal tube if secretions are excessive or nasal CPAP fails to maintain improvement but can usually be extubated early and CPAP continued by nasal cannula. This avoids prolonged intubation and reduces the incidence of secondary infection. In this series three of the intubated patients had bacterial colonisation of the airway compared with only one of the infants who were not intubated.
We thank our paediatrician colleagues for permission to report the cases, Dr P Weller for helpful comments, and Mrs Carole McSheen for typing the manuscript.

\section{References}

${ }^{1}$ Court SDM. The management and outcome in children admitted to hospital. Postgrad Med F 1973;49:812-7.

${ }^{2}$ Elderkin FM, Gardner PS, Turk DC, White AC. Aetiology and management of bronchiolitis and pneumonia in childhood. Br Med F 1965;ii: 722-7.

${ }^{3}$ Heycock JB, Noble TC. 1,230 cases of acute bronchiolitis in infancy. Br Med F 1962;ii:879-88.

4 Wohl MEB, Chernick V. Bronchiolitis. Am Rev Respir Dis 1978;118: 759-81

5 Phelan PD, Williams HE, Stocks JG, Freeman M. Artificial ventilation in the management of respiratory insufficiency in acute bronchiolitis. Aust Paediatr $\mathcal{F}$ 1968;4:223-8.

${ }^{6}$ Downes JJ, Wood DW, Striker TW, Haddad C. Acute respiratory failure in infants with bronchiolitis. Anesthesiology $1968 ; 29: 426-34$.

${ }^{7}$ Campbell EJM. Respiratory failure. Br Med f 1965;i:1451-60.

${ }^{8}$ Jones RS, Owen-Thomas JB. Care of the critically ill child. London: Edward Arnold, 1971:110-25.

- Milner AD. Respiratory emergencies. In: Black JA, ed. Paediatric emergencies. London: Butterworths, 1976:246-81.

10 Wohl MEB, Stigol LC, Mead J. Resistance of total respiratory system in healthy infants, and infants with bronchiolitis. Pediatrics 1969;43: 495-509.

1 Phelan PD, Williams HE, Freeman M. The disturbance of ventilation in acute viral bronchiolitis. Aust Paediatr $\mathcal{F} 1968 ; 4: 96-104$.

${ }^{12}$ Reynolds EOR. Arterial blood gas tensions in acute disease of the lower respiratory tract in infancy. $\mathrm{Br} \mathrm{Med} \mathcal{F} 1963 ; \mathrm{i}: 1192-5$.

13 Simpson $\mathrm{H}$, Flenley DC. Arterial blood gas tensions and $\mathrm{pH}$ in acute lower respiratory tract infections in infancy and childhood. Lancet $1967 ; \mathrm{i}: 7-12$.

14 Simpson H, Matthew DJ, Habel AH, George EL. Acute respiratory failure in bronchiolitis and pneumonia in infancy. Modes of presentation and treatment. $\mathrm{Br} M e d \mathcal{F} 1974 ;$ ii :632-6.

15 Phelan PD, Stocks JG. Management of severe viral bronchiolitis and severe acute asthma. Arch Dis Child 1974;49:143-8.

${ }^{16}$ Comroe JH. Physiology of respiration. Chicago: Year Book Medical Publishers, 1966.

(Accepted 11 September 1981)

\section{SHORT REPORTS}

\section{Death due to overdose of nefopam}

Nefopam is recommended for the relief of acute and chronic pain. Though chemically and pharmacologically distinct from both narcotic and anti-inflammatory analgesic agents, it is one-fifth to one-half as potent as morphine, and its mode of action is unknown. ${ }^{1}$ It appears to have low toxicity and a low potential for addiction and abuse. We report the clinical and pathological features of a patient who died due to an acute overdose of this drug, together with details of nine patients who recovered after overdosage.

\section{Case reports}

A 30-year-old woman was found unconscious by the roadside, having apparently fallen from her moped. Apart from a suicide note in the basket of the moped there was no indication of what had occurred. Although conscious during transport to hospital, she developed generalised clonic convulsions occurring at 30-second intervals and respiratory arrest ensued. After intubation and resuscitative measures gastric lavage yielded a white sediment. In the intensive care unit she was sedated and ventilated; she was deeply unconscious with reacting pupils, absent conjugate eye movements, flaccid paralysis, and extensor plantar reflexes. Electrocardiography showed a rate of 150 with first-degree block and right bundle-branch block. After five hours she had a fever of $41.9 \mathrm{C}$. She subsequently developed gross haematuria and oliguria. Coagulation studies, initially slightly abnormal later showed considerable prolongation of the prothrombin time ( $31 \mathrm{~s} v 13 \mathrm{~s}$ ), partial thromboplastin time (90s $v 44 \mathrm{~s})$, and thrombin time (15 s $v 10 \mathrm{~s})$. Platelet count was $101 \times 10^{9} / 1$.

Her condition deteriorated with alternating nodal and ventricular tachycardia and anuria, which was unresponsive to fluid challenge or diuretics. She died 19 hours after admission after two cardiac arrests. At necropsy the brain showed considerable oedema with early coning. Both lungs were acutely congested with focal areas of parenchymal haemorrhage, and there was moderate pulmonary oedema and small pleural effusions. The liver, spleen, and kidneys were acutely congested and there was diffuse eosinophilic swelling of the renal tubular epithelium. The gastric mucosa was intensely congested with patchy epithelial necrosis, and the stomach contained $340 \mathrm{ml}$ of pink-stained white granular material.

Extensive toxicological investigations were carried out using thin-layer chromatography, ultraviolet spectrophotometry, gas-liquid chromatography, and mass spectrometry. No drug other than nefopam was detected, and a serum concentration of $11.9 \mathrm{mg} / 1$ was measured in a postmortem sample. Therapeutic doses of nefopam give rise to peak plasma concentrations of about $0.1 \mathrm{mg} / 1,{ }^{1}$ and it was concluded that death was due to a massive overdose of nefopam.

Nefopam was first marketed in the UK in 1978, since when seven cases of overdosage have been followed up through the National Poisons Information Service and a further two have been reported to the manufacturers. These are summarised in the table. Plasma concentrations were measured in one case (case 9). A concentration of $3.8 \mathrm{mg} / \mathrm{l}$ was found at three hours in this patient, who had distinct clinical evidence of toxicity.

\section{Comment}

Few data are available on the toxicology of nefopam in man. Dogs receiving $40-80 \mathrm{mg} / \mathrm{kg} /$ day show stimulation of the central nervous system characterised by excited behaviour and convulsions, ${ }^{2}$ and the median lethal dose in dogs is about $20 \mathrm{mg} / \mathrm{kg}$ intravenously and $100-200 \mathrm{mg} / \mathrm{kg}$ by mouth. ${ }^{3}$ The present case is the first known death due to nefopam in man.

From the nine non-fatal cases reported a clinical pattern of nefopam toxicity may be discerned. Convulsions, hallucinations, and agitation appear to be the neurological features of overdosage, and tachycardia 